\title{
Chloride dependent amino acid transport in the human small intestine
}

\author{
L K Munck
}

\begin{abstract}
Carriers of $\beta$ amino acids and imino acids in the small intestine of rabbits and guinea pigs are chloride dependent, and a cotransport of chloride, sodium, and 2-methylaminoisobutyric acid has been shown. This study examines the chloride dependence of amino acid transport in the human small intestine. The steady state tissue uptake of amino acids, given as the ratio between substrate concentration in intracellular and extracellular water after 35 minutes incubation at $37^{\circ} \mathrm{C}$, was determined in mucosal biopsy specimens from the duodenum of patients undergoing diagnostic upper endoscopy and compared using one way analysis of variance. Uptake of leucine and $\alpha$-methyl-D-glucoside in the duodenum and the distal ileum did not differ. The accumulation of all substrates was sodium dependent. In the absence of mucosal chloride the uptake of taurine, glycine, and 2-methyl-aminoisobutyric acid was significantly reduced while that of leucine and $\alpha$-methyl-D-glucoside was unaffected and the reduction of $\beta$ alanine uptake not statistically significant. Uptake of 2-methyl-aminoisobutyric acid and proline showed mutual inhibition. Leucine did not reduce uptake of the $\beta$ amino acids. In conclusion, chloride dependent transport processes for 2-methyl-aminoisobutyric acid, taurine, and glycine are present in the human small intestine.

(Gut 1995; 36: 215-219)
\end{abstract}

Keywords: biological transport, amino acids, chlorides, human duodenum.

Shortly after Crane $^{1}$ proposed the sodium gradient hypothesis to account for the active transport of nutrients across the mucosal membrane of enterocytes, Vidaver ${ }^{2}$ showed a nearly complete inhibition of the sodium dependent component of glycine uptake by pigeon red cells by removal of chloride. After a considerable delay studies on kidney tubular ${ }^{3}$ and intestinal ${ }^{4}$ epithelia were published. In the rabbit small intestine, the sodium dependent carrier of imino acids, 2-methyl-aminoisobutyric acid and proline, ${ }^{5}$ and the carriers of taurine $^{6}$ and $\beta$ alanine ${ }^{7}$ are chloride dependent. By contrast, the high affinity taurine carrier is the only chloride dependent carrier present in the rat small intestine. ${ }^{89}$ This difference in chloride dependence emphasises the significant differences in carrier specificity seen between species. ${ }^{8}$
Chloride dependence of amino acid transport could reflect either a need for chloride merely as a catalytic activator or a necessity of chloride ion cotransport with the amino acid and sodium. In the second case the repeatedly observed activation stoichiometry of 2 sodium: 1 chloride: 1 amino acid ${ }^{3-9}$ would still be consistent with the rheogenic nature of the transport. Data reported for $\operatorname{dog}^{3}$ and rabbit ${ }^{10}$ kidney proximal tubule and for Erhlich ascites tumour cells ${ }^{11}$ strongly suggest cotransport of chloride ions and $\beta$ amino acids. We have recently considered the question of cotransport in an intestinal epithelia by measuring unidirectional influx across the brush border membrane in the rabbit distal ileum and have shown cotransport of sodium, chloride, and 2-methyl-aminoisobutyric acid ${ }^{12}$ with a influx stoichiometry of $2: 1: 1$ as previously shown in an ion activation study. ${ }^{5}$ This study presents a survey of chloride dependent amino acid transport in the human small intestine using the technique of steady state mucosal uptake.

\section{Methods}

SUBJECTS AND MATERIAL

The study was approved by the ethical committee of Copenhagen County (KF V92-324) and written informed consent was obtained before the examination. Biopsy specimens (Olympus biopsy forceps without a spear; FB24K) were collected from 83 patients (mean age 64 years, range 27-91) in whom diagnostic upper endoscopy showed a macroscopic normal duodenal mucosa and from the distal ileum of one patient age 24 . Patients with severe cardiopulmonary or cerebral insufficiency, with subnormal concentrations of plasma albumin, and those receiving benzodiazepines were not considered for the study.

Normal sodium and chloride medium was prepared from a phosphate buffer with a $\mathrm{pH}$ of $7 \cdot 4$, and had a composition in mmol/l of: $\mathrm{NaCl}$ $140, \mathrm{~K}^{+} 8, \mathrm{Ca}^{2+} 2 \cdot 6, \mathrm{Mg}^{2+} 1$, phosphate 8 , and $\mathrm{SO}_{4}{ }^{2-} 1$. Sodium free solutions were prepared by substituting $N$-methyl-D-glucamine $\mathrm{HCl}$ for $\mathrm{NaCl}$, and chloride free solutions by substituting sodium isethionate for $\mathrm{NaCl}$. Isosmolality was maintained in inhibition studies by adding equivalent concentrations of D-mannitol to the control solutions. $\left[{ }^{14} \mathrm{C}\right]$-labelled amino acids and $\alpha$-methyl-D-glucoside (1-O-methyl-Dglucopyranoside), a D-glucose analogue, and $\left[{ }^{3} \mathrm{H}\right]$-labelled polyethylene glycol (PEG, molecular weight 4000) were purchased from New England Nuclear.

Department of
Medical Physiology, The Panum Instit of Medical Physiology and Huclear Medicine, University of Copenhagen, Denmark May 1994
} 
STEADY STATE MUCOSAL UPTAKE

Steady state mucosal uptake of $\left[{ }^{14} \mathrm{C}\right]$-labelled substrates in duodenal mucosal biopsy specimens was measured using the method described for rabbit ileum. ${ }^{13}$ Two to four specimens from the descending or horizontal part of the duodenum of each patient were collected in ice cold, preoxygenated buffer. Within five minutes, the specimens were blotted on filter paper and transferred to three Erlenmeyer flasks containing $3000 \mu \mathrm{l}$ isosmotic media with the composition given above, gassed with $100 \%$ oxygen in a $37^{\circ} \mathrm{C}$ shaking water bath, and incubated for 35 minutes. Specimens used for studying the ion dependent substrate accumulation were collected in chloride free buffer. In these studies one flask contained normal sodium and chloride medium (140 $\mathrm{mmol} / \mathrm{l} \mathrm{NaCl}$ ), one sodium free medium, and one chloride free medium. $\left[{ }^{3} \mathrm{H}\right]-\mathrm{PEG}$ was used as a marker of the extracellular space. $\left[{ }^{14} \mathrm{C}\right]$-labelled substrates, taurine $(5 \mu \mathrm{mol} / \mathrm{l}), \beta$ alanine $(5 \mu \mathrm{mol} / \mathrm{l})$, leucine $(1 \mathrm{mmol} / \mathrm{l})$, glycine (1 $\mathrm{mmol} / \mathrm{l}), 2$-methyl-aminoisobutyric acid $(1 \mathrm{mmol} / \mathrm{l})$ or $\alpha$-methyl-D-glucoside $(1 \mathrm{mmol} / \mathrm{l})$ were used as substrates. Five $\mathrm{mmol} / \mathrm{l} \mathrm{D}$-glucose was present in all incubation mixtures, except when $\alpha$-methyl-D-glucoside uptake was measured.

After incubation the wet weight of all specimens $(7 \cdot 0 \pm 0.2 \mathrm{mg})$ was determined. Subsequently, the specimens were extracted for 18 hours in $0.1 \mathrm{M} \mathrm{HNO}_{3}$, and then dried for six hours at about $90^{\circ} \mathrm{C}$. The dry weight fraction was $5 \cdot 5 \pm 0 \cdot 1 \%$. The $\left[{ }^{3} \mathrm{H}\right]$ and $\left[{ }^{14} \mathrm{C}\right]$ activities of the incubation fluids and tissue extracts were determined (Tri-Carb $2200 \mathrm{CA}$, Packard). The distribution ratio between substrate concentration $\left(\left[{ }^{14} \mathrm{C}\right]\right.$ activity) in intracellular water and in extracellular water (incubation fluid) was calculated after correction for extracellular space. The extracellular space calculated from the $\left[{ }^{3} \mathrm{H}\right]$ activity of the extract was $34.0 \pm 0.5 \%$ assuming equilibration of $\left[{ }^{3} \mathrm{H}\right]-\mathrm{PEG}$ between extracellular water and incubation fluid. Sodium and chloride concentrations were measured in the used incubations fluids by means of a flame photometer (FLM2, Radiometer, Copenhagen) and chloride titration (CMT 10, Radiometer, Copenhagen), respectively.

\section{STATISTICS}

The results of pooled data from four to 11 patients are given as mean (SEM). The inhibitory effect of one substrate on the accumulation of another was evaluated by the paired Student's $t$ test. In studies of the time course of $\alpha$-methyl-D-glucoside uptake and of ion dependence of substrate uptake four and three specimens, respectively, from each patient were paired and the results evaluated by one way analysis of variance (SigmaStat $1 \cdot 0$, Jandel Scientifics). Initially, it was tested whether the results of each group were drawn from a normally distributed population with the same variance. When confirmed, the ratio between the estimated population variance between groups with within groups, the $F$ statistic, was calculated. Given that a significant difference between groups was found, multiple comparisons between group pairs was performed using the StudentNeuman-Keuls method. When the equal variance test failed (normality test passed in all cases) the $H$ statistic was calculated using the Kruskal-Wallis test. When $\mathrm{H}$ was large multiple pairwise comparisons were performed using the Student-Neuman-Keuls test on ranks. Probability values less than 0.05 were considered statistically significant throughout.

\section{Results}

\section{VALIDATION OF THE TECHNIQUE}

The incubation time required to obtain steady state was determined by measuring uptake of $\alpha$-methyl-D-glucoside. Four specimens from each of seven patients were incubated for 10-40 minutes (Figure). Uptake at 30 minutes did not differ from that at 40 minutes. Uptake of leucine $(7 \cdot 7 ; n=2)$ and $\alpha$-methyl-D-glucoside $(14 \cdot 4 ; n=2)$ in specimens obtained from the distal ileum of one patient during colonoscopy were within the range of ratios obtained with specimens from the duodenum. Consequently, duodenal specimens and incubation periods of 35 minutes were used for further studies.

\section{ION DEPENDENCE OF AMINO ACID UPTAKE}

$\alpha$-methyl-D-glucoside is a non-metabolisable D-glucose analogue, which is not transported by the sodium independent carrier on the basolateral membrane. The ratio of 13.8 obtained at $140 \mathrm{mmol} / 1 \mathrm{NaCl}$ (Table) reflects the balance between the rate of secondary transport across the mucosal membrane of enterocytes tending to increase and passive leaks on the carrier and by diffusion tending to reduce the intracellular concentration.

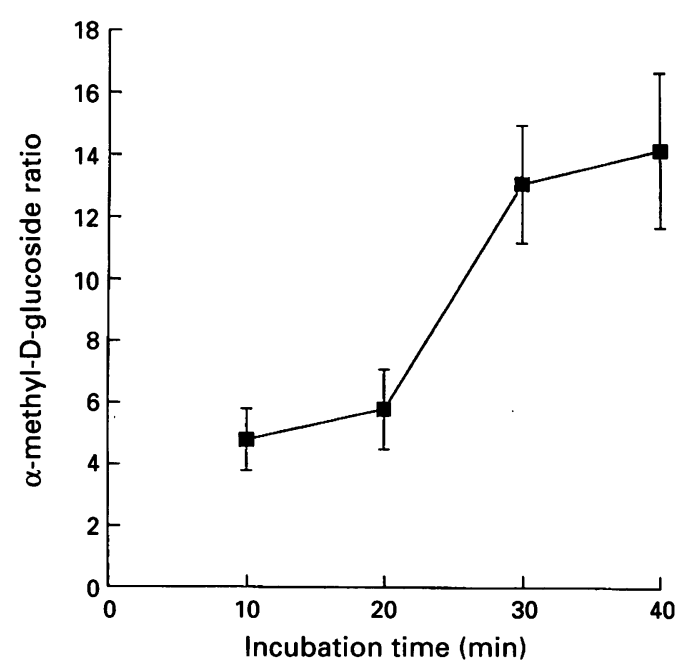

Mucosal uptake of $\alpha$-methyl-D-glucoside in human small intestine. The mucosal uptake given as the ratio of distribution between intracellular and extracellular water was determined in four biopsy specimens from the same patient as a function of incubation time. Findings are mean (SEM) of seven paired findings. The ratios obtained at 30 and 40 minutes do not differ (NS by one way analysis of variance) pointing to a steady state. 
Ion dependency of steady state mucosal uptake of amino acids in human small intestine

\begin{tabular}{lrlll}
\hline & $140 \mathrm{NaCl}$ & \multicolumn{1}{l}{$0 \mathrm{Na}$} & \multicolumn{1}{l}{$0 \mathrm{Cl}$} & $\begin{array}{l}\text { Paired biopsy } \\
\text { specimens }(n)\end{array}$ \\
\hline 2-Methyl-aminoisobutyric acid & $1 \cdot 6(0 \cdot 1)$ & $0 \cdot 9(0 \cdot 1)^{\star}$ & $1 \cdot 2(0 \cdot 1)^{\star} \dagger$ & 15 \\
$\beta$ alanine & $1 \cdot 8(0 \cdot 3)$ & $0 \cdot 6(0 \cdot 1)^{\star}$ & $1 \cdot 3(0 \cdot 2) \dagger$ & 11 \\
Taurine & $1 \cdot 6(0 \cdot 1)$ & $0 \cdot 9(0 \cdot 1)^{\star}$ & $1 \cdot 2(0 \cdot 1)^{\star} \dagger$ & 11 \\
Leucine & $5 \cdot 9(0 \cdot 9)$ & $1 \cdot 5(0 \cdot 1)^{\star}$ & $4 \cdot 7(0 \cdot 8) \dagger$ & 12 \\
Proline & $2 \cdot 0(0 \cdot 2)$ & $1 \cdot 6(0 \cdot 2)$ & $2 \cdot 1(0 \cdot 5)$ & 4 \\
Glycine & $1 \cdot 9(0 \cdot 1)$ & $1 \cdot 0(0 \cdot 1)^{\star}$ & $1 \cdot 3(0 \cdot 1)^{\star} \dagger$ & 7 \\
$\alpha$-methyl-D-glucoside & $13 \cdot 8(1 \cdot 6)$ & $1 \cdot 0(0 \cdot 1)^{\bullet}$ & $13 \cdot 8(2 \cdot 2) \dagger$ & 6 \\
\hline
\end{tabular}

The steady state mucosal uptake is given as the ratio between substrate concentration in intracellular and extracellular water after 35 minutes incubation in the presence of $140 \mathrm{mmol} / \mathrm{s}$ $\mathrm{NaCl}, 0 \mathrm{mmol} / / \mathrm{Na}^{+}$, and $0 \mathrm{mmol} / / \mathrm{Cl}^{-}$, respectively. Five mmol/ $\mathrm{D}$-glucose was present except when measuring uptake of $\alpha$-methyl-D-glucoside. The concentration of taurine and $\beta$ alanine when measuring uptake of $\alpha$-methyl-D-glucoside. The concentrati
was $5 \mu \mathrm{mol} / 1$ and the other substrates were studied at $1 \mathrm{mmol} / 1$.

$\star$ Denotes $\mathrm{p}<0.05$ by one way analysis of variance in comparison with $140 \mathrm{mM} \mathrm{NaCl}$ and $t \mathrm{p}<0.05$ in comparison with $0 \mathrm{mM} \mathrm{Na}{ }^{+}$. Results are mean (SEM).

Because of the leaks ${ }^{14}$ and because the enterocyte cell mass represents only a fraction of total mucosal tissue the concentration gradient obtained is much less than the theoretical maximum. Uptake of $\alpha$-methyl-D-glucoside was sodium dependent but independent of the mucosal chloride concentration (Table).

The Table gives the results of steady state mucosal uptake of amino acids. Mucosal uptake in excess of unity was shown for all substrates at $140 \mathrm{mmol} / \mathrm{l} \mathrm{NaCl}$ and was reduced in the absence of sodium. For the two neutral amino acids proline and leucine uptake was still evident in the absence of mucosal sodium. Sodium concentrations in the utilised sodium free incubation solutions were $0-1$ $\mathrm{mmol} / \mathrm{l}$. Uptake of leucine, proline, and $\alpha$-methyl-D-glucoside was chloride independent, and the ratios obtained were not different from those obtained at $140 \mathrm{mmol} / \mathrm{l}$ $\mathrm{NaCl}$ (Table; NS). Uptake of taurine and 2-methyl-aminoisobutyric acid, a classic and non-metabolisable substrate for the imino acid carrier in other species, ${ }^{15} 16$ was chloride dependent (Table; $p<0 \cdot 05$ ). Uptake of $\beta$ alanine was lower in the absence of chloride without the difference reaching statistical significance (Table; $0 \cdot 10<\mathrm{p}<0 \cdot 05$ ). Uptake of all chloride independent substrates except proline was significantly higher in the absence of chloride than in the absence of sodium (Table; $\mathrm{p}<0.05$ ). Chloride concentrations in the utilised chloride free incubation solutions were between 1 and $6 \mathrm{mmol} / \mathrm{l}$.

INTERACTIONS BETWEEN AMINO ACIDS

In the rabbit small intestine proline is transported in part on the imino acid carrier. ${ }^{15}$ The steady state mucosal uptake of 2-methylaminoisobutyric acid $(1 \mathrm{mmol} / \mathrm{l})$ measured in paired experiments at $140 \mathrm{mmol} / \mathrm{l} \mathrm{NaCl}$ and $5 \mathrm{mmol} / \mathrm{l} \mathrm{D}$-glucose was $2.0(0.2)$ in the presence of $40 \mathrm{mmol} / 1 \mathrm{D}$-mannitol and 0.5 $(0 \cdot 1)$ in the presence of $40 \mathrm{mmol} / \mathrm{l}$ proline $(n=10 ; p<0.001)$. In the reverse experiment uptake of proline $(1 \mathrm{mmol} / \mathrm{l})$ was $1 \cdot 4(0 \cdot 1)$ in the presence of $40 \mathrm{mmol} / \mathrm{l} \mathrm{D}$-mannitol and $1 \cdot 2$ $(0 \cdot 1)$ with $40 \mathrm{mmol} / \mathrm{l}$ 2-methyl-aminoisobutyric acid present $(n=12 ; p<0 \cdot 001)$. Uptake of $\beta$ alanine (5 $\mu \mathrm{mol} / 1 ; \mathrm{n}=6)$ and taurine (5 $\mu \mathrm{mol} / \mathrm{l} ; \mathrm{n}=8)$ was $1.5(0 \cdot 1)$ and $1.4(0 \cdot 1)$, respectively in the presence of $10 \mathrm{mmol} / \mathrm{l}$ D-mannitol and $1 \cdot 7(0 \cdot 1)$, respectively $1 \cdot 4$
$(0 \cdot 1)$ in the presence of $10 \mathrm{mmol} / \mathrm{l}$ leucine (NS).

\section{Discussion}

Measurements of the in vitro steady state mucosal uptake were used 30 years ago to show the intestinal transport defect in mucosal biopsy specimens from the jejunum of patients with cystinuria. ${ }^{17-19}$ As in this study (Figure) a steady state was reached after about 30 minutes of incubation. ${ }^{17} 18$ The ratio between the concentration in intracellular and extracellular water obtained in this study were lower than the values of approximately 5 for glycine ${ }^{17}$ and 10 for leucine ${ }^{18}$ reported previously. As we obtained similar values in the distal ileum and in the duodenum the difference is probably not explained by the fact that the former reports used specimens from the distal duodenum. The difference is more probably explained by the difference in substrate concentrations used. By using very low, micromolar concentrations of amino acids leaks and passive back diffusion are reduced significantly. ${ }^{20}$ Nevertheless, the low ratios obtained in this study do not discredit our results.

This study shows that transport of imino acids, taurine, glycine, and perhaps also $\beta$ alanine in the human small intestine requires chloride in addition to sodium. Transport of $\alpha$-methyl-glucoside, leucine, and proline was unchanged in the absence of chloride showing that the removal of mucosal chloride does not affect the membrane potential significantly. ${ }^{812}$ Uptake from the nominally chloride free media was not reduced to the value seen with nominally sodium free solutions. This was probably because of a partial activation of the carriers by the $1-6 \mathrm{mmol} / 1$ chloride present in the incubation solutions at the termination of the experiments. Because of trapping in the unstirred water layer and recycling across the mucosal membrane the chloride concentrations at the carrier sites were most probably higher than indicated by end of experiment measurements. Thus, taurine transport in rabbit small intestine was half maximal at $7 \mathrm{mmol} / \mathrm{l}$ chloride. ${ }^{7}$ The chloride dependent uptake of the non-metabolisable imino acid 2-methyl-aminoisobutyric acid make it unlikely that chloride dependence of transport could reflect chloride dependent amino acid metabolism. The lack of chloride dependent proline accumulation should be expected if proline is also carried on a high capacity carrier of neutral amino acids as in the rabbit. ${ }^{151621}$ Likewise, a conceivable explanation of the persisting, but minute uptake of leucine and glycine in the absence of sodium would be uptake by sodium independent transport systems described in other species. ${ }^{15162122}$ The low $(0-1 \mathrm{mmol} / \mathrm{l})$ sodium concentrations in the utilised incubation solutions seem to rule out notable activation of the sodium dependent transport systems.

The individual carriers of amino acids in the human small intestine are not well characterised. ${ }^{23-25}$ The inhibition of 2-methylaminoisobutyric acid accumulation by proline 
and vice versa shows that these imino acids are transported at least in part on a common carrier different from the carrier of neutral amino acids as is the case for the imino acid carrier of rabbit small intestine. ${ }^{15}$ In addition to the taurine carrier, some species possess a second carrier of $\beta$ amino acids that also accepts neutral amino acids such as leucine. ${ }^{72226}$ The lack of inhibition of both taurine and $\beta$ alanine uptake by leucine in the human duodenum suggests that this carrier is not present in the human small intestine. The chloride dependence of glycine uptake, however, would point to the existence of such a carrier. ${ }^{26}$

The pattern of chloride dependence reported here is identical to results obtained in rabbit, ${ }^{5-7} 26$ guinea pig, ${ }^{8}$ and human colon carcinoma cells, ${ }^{27}$ similar to that of the pig (L K Munck et al, unpublished findings), and very different from that of the rat, ${ }^{8}$ which seems to be a poor model for human intestinal carriers of amino acids. This would suggest that carriers of amino acids in the human small intestine are similar to those described in the strictly herbivorous rabbit, the guinea pig, and the pig (L K Munck et al, unpublished findings). Furthermore, the taurine carrier emerges as ubiquitous.

We have previously provided evidence of cotransport of both chloride and sodium with 2-methyl-aminoisobutyric acid across rabbit small intestinal mucosa ${ }^{12}$ and cotransport of chloride with taurine and $\beta$ alanine has been shown in renal epithelia. ${ }^{3102829}$ and Ehrlich ascites tumour cells. ${ }^{11}$ The present results give an indication that amino acids and chloride may also be cotransported in the human small intestine. The physiological significance of cotransport of chloride, ${ }^{3} 10-1230$ in addition to sodium, with amino acids remains to be elucidated as does the finding of such a cotransport in human enterocytes.

Coupling of solute transport to more ions permits the enterocyte to establish and maintain a higher concentration gradient across the mucosal membrane. Chloride is close to its equilibrium distribution, however, and cannot contribute much to the efficacy of a recapture system. Amino acids are organic osmolytes. $^{31}$ Taurine is important in volume regulation in Erhlich ascites tumour cells ${ }^{11}$ and in Madin-Darby canine kidney cells ${ }^{32}$ and could be of importance in other mammalian cells. Interestingly, Thwaites et al have provided evidence of proton gradient driven mucosal transport of 2-methyl-aminoisobutyric acid, proline, and $\beta$ alanine but not leucine in human intestinal Caco-2 cells and of $\beta$ alanine stimulated proton influx. ${ }^{33} 34$ The similarity between the specificities of the chloride dependent and the proton dependent amino acid transport systems raises the question whether these two dependencies might be coexistent in the human small intestine. Indirect evidence actually pointed to cotransport of $1 \mathrm{H}^{+}: 2 \mathrm{Na}^{+}: 1 \mathrm{CL}^{-}: 1 \beta$ alanine in rabbit proximal tubule. ${ }^{28}$ In conclusion, chloride dependent transport of $\beta$ amino acids, glycine, and imino acids in the human small intestine is shown and by analogy with animal studies a cotransport of these amino acids and chloride, in addition to sodium, across the mucosal membrane of enterocytes is suggested. These functional properties could be of value in the discrimination of amino acid transport systems in the human small intestine.

This work was supported by the NOVO Foundation, the Danish Medical Research Council, and the Danish Medical Association.

1 Crane RK. Hypothesis for mechanism of intestinal active transport of sugars. Federation Proc 1962; 21: 891-5.

2 Vidaver GA. Mucate inhibition of glycine entry into pigeon red cells. Biochemistry 1964; 3: 799-803.

3 Turner RJ. $\beta$-amino acid transport across the renal brush-border membrane is coupled to both $\mathrm{Na}$ and $\mathrm{Cl}$ f Biol Chem 1986; 261: 16060-6.

4 Bogé G, Rigal A. A chloride requirement for $\mathrm{Na}^{+}$-dependent amino-acid transport by brush border membrane vesicles isolated from the intestine of a mediterranean teleost (boops salpa). Biochim Biophys Acta 1981; 649: teleost

5 Munck LK, Munck BG. Chloride-dependence of amino acid transport in rabbit ileum. Biochim Biophys Acta 1990; 1027: $17-20$

6 Miyamoto Y, Tiruppathi C, Ganapathy V, Leibach FH. Active transport of taurine in rabbit jejunal brush-border membrane vesicles. Am f Physiol 1989; 257: G65-72.

7 Munck LK, Munck BG. Distinction between chloridedependent transport systems for taurine and $\beta$-alanine in rabbit ileum. Am f Physiol 1992; 262: G609-15.

8 Munck LK, Munck BG. Chloride-dependent intestinal transport of imino- and $\beta$-amino acids in the guinea pig and rat. Am $\mathcal{F}$ Physiol 1994; 266: R997-1007.

9 Barnard JA, Thaxter S, Kikuchi K, Ghishan FK. Taurine transport by rat intestine. Am f Physiol 1988; 254: transport

10 Wolff NA, Kinne R. Taurine transport by rabbit kidney brush-border membranes: coupling to sodium, chloride, and the membrane potential. $\mathcal{F}$ Membr Biol 1988; 102: 131-9.

11 Lambert IH, Hoffmann EK. Regulation of taurine transport in Ehrlich ascites tumor cells. $\mathcal{F}$ Membr Biol 1993; 131: 67-79.

12 Munck LK. Cotransport of 2-amino-isobutyric acid and chloride in rabbit small intestine. Am f Physiol 1993; 265: G979-86.

13 Schultz SG, Fuisz RE, Curran PF. Amino acid and sugar transport in rabbit ileum. $\mathcal{F}$ Gen Physiol 1966; 49: 849-66.

14 Kimmich GA. Membrane potentials and the mechanism of intestinal $\mathrm{Na}^{+}$-dependent sugar transport. $\mathcal{F} \mathrm{Membr}$ Biol intestinal $\mathrm{Na}^{+}$-de

15 Munck BG. Transport of imino acids and non- $\alpha$-amino acids across the brush-border membrane of the rabbit. f Membr Biol 1985; 83: 15-24.

16 Stevens BR, Ross HJ, Wright EM. Multiple transport pathways for neutral amino acids in rabbit jejunal brush border membrane vesicles. F Membr Biol 1982; 66: 213-25.

17 Thier SO, Segal S, Fox M, Blair A, Rosenberg LE. Cystinuria: defective intestinal transport of dibasic amino acids and cystine. $\mathcal{F}$ Clin Invest 1965; 44: 442-8.

18 McCarthy CF, Borland JL, Lynch HJ, Owen EE, Tyor MP. Defective uptake of basic amino acids and L-cystine by intestinal mucosa of patients with cystinuria. $\mathcal{F}$ Clin Invest intestinal mucosa of

19 Segal S, Their SO. Cystinuria. In: Scriver CR, Beaudet AL, Sly WS, Valle D, eds. The metabolic basis of inherited disease. Sixth ed. New York: McGraw-Hill, 1989: 2479-96

20 Munck BG, Schultz SG. Lysine transport across isolated rabbit ileum. f Gen Physiol 1969; 53: 157-82.

21 Paterson JYF, Sépulveda FV, Smith MW. Two-carrie influx of neutral amino acids into rabbit ileal mucosa. f Physiol 1979; 292: 339-50.

22 Van Winkle LJ. Amino acid transport in developing animal oocytes and early conceptuses. Biochim Biophys Acta 1988; 947: 173-208.

23 Rajendran VM, Harig JM, Adams MB, Ramaswamy K Transport of acidic amino acids by human jejunal brushTransport of acidic amino acids by human jejunal brush-
border membrane vesicles. Am $\neq$ Physiol 1987; 252: G33-9.

24 Harig JM, Barry JA, Rajendran VM, Soergel $\mathrm{KH}$, Ramaswamy K. D-Glucose and L-leucine transport by human intestinal brush-border membrane vesicles. $A m \mathcal{F}$ Physiol 1989; 256: G618-23.

25 Delaquis A, Malo C. Studies of neutral amino acid transport in fetal and adult jejunal brush-border membrane vesicles (BBMV). Gastroenterology 1993; 104: A241.

26 Munck LK, Munck BG. Lack of separate, chloride-dependent carriers of glycine and glutamic acid in rat, guinea pig and rabbit small intestine. $Z$ Gastroenterol 1993; 31: 575 .

27 Tiruppathi C, Brandsch M, Miyamoto Y, Ganapathy V, Leibach FH. Constitutive expression of the taurine transporter in a human colon carcinoma cell line. Am $\mathcal{f}$ Physiol 1992; 263: G625-31.

28 Jessen H, Sheikh MI. Stoichiometric studies of $\beta$-alanine transporters in rabbit proximal tubule. Biochem $\mathcal{F} 1991$; 227: 891-4.

29 Jessen H, Sheikh MI. Renal transport of taurine in luminal 
membrane vesicles from rabbit proximal tubule. Biochim Biophys Acta 1991; 1064: 189-98.

30 Stevens BR. Vertebrate intestine apical membrane mecha nisms of organic nutrient transport. Am $\mathcal{f}$ Physiol 1992; 263: R458-63.

31 Chamberlin ME, Strange K. Anisosomotic cell volume regulation: a comparative view. Am $\mathcal{F}$ Physiol 1989; 257:

32 Uchida S, Nakanishi T, Kwon HM, Preston AS, Handler JS. Taurine behaves as an osmolyte in Madin-Darby anine kidney cells. Protection by polarized, regulated transport of taurine. $\mathcal{f}$ Clin Invest 1991; 88: 656-62.

33 Thwaites DT, McEwan GTA, Brown CDA, Hirst BH, Simmons NL. $\mathrm{Na}^{+}$-independent, $\mathrm{H}^{+}$-coupled transepithelial $\beta$-alanine absorption by human intestinal Caco-2 cell monolayers. $\mathcal{F}$ Biol Chem 1993; 268: 18438-41.

34 Thwaites DT, McEwan GTA, Hirst BH, Simmons NL Thwaites DT, McEwan GTA, Hirst BH, Simmons NL.
Proton gradient driven $\alpha$-methylaminoisobutyric acid transport in human intestinal Caco-2 cells. F Physiol 1994; 475: $93 \mathrm{P}$. 